\title{
Insulin-like growth factor-1 isoforms in rat hepatocytes and cholangiocytes and their involvement in protection against cholestatic injury
}

\author{
Manuela Gatto ${ }^{1,2}$, Veronica Drudi-Metalli ${ }^{1}$, Alessia Torrice ${ }^{1}$, Gianfranco Alpini ${ }^{3}$, Alfredo Cantafora ${ }^{1}$, Ida Blotta ${ }^{1}$ \\ and Domenico Alvaro ${ }^{1,2}$
}

A 'locally acting' IGF1 (insulin-like growth factor 1 ) isoform has been recently identified in the skeletal muscle and neural tissues where it accelerates injury repair. No information exist on the expression and function of IGF1 isoforms in the liver. We investigated IGF1 isoforms in rat hepatocytes and cholangiocytes and evaluated their involvement in cell proliferation or damage induced by experimental cholestasis (bile duct ligation, BDL) or hydrophobic bile salts. IGF1 isoforms were analyzed by real-time PCR by using $\beta$-actin as internal reference. In both hepatocytes and cholangiocytes, the 'locally acting' IGF1 isoform (XO6108) and 'circulating' IGF1 isoform (NM_178866) represented respectively 44 and $52 \%$ of the total IGF1. Basal mRNAs for both 'locally acting' and 'circulating' IGF1 isoforms were higher $(P<0.05)$ in hepatocytes than cholangiocytes. After BDL for $3 \mathrm{~h}$, the 'locally acting' IGF1 isoform decreased threefold $(P<0.05)$ in hepatocytes but remained stable in cholangiocytes with respect to sham-controls. After 1 week of BDL, hepatocytes displayed a further fivefold decrease of 'locally acting' IGF1 mRNA. In contrast, cholangiocytes showed an eightfold increase of the 'locally acting' IGF1 mRNA. The effect of $3 \mathrm{~h}$ of BDL on IGF1 isoforms was reproduced in vitro by incubation with glycochenodeoxycholate (GCDC). The cytotoxic effects (inhibition of proliferation and induction of apoptosis) of GCDC on isolated cholangiocytes were more pronounced after selective silencing (SiRNA) of 'locally acting' than 'circulating' IGF1 isoform. Rat hepatocytes and cholangiocytes express the 'locally acting' IGF1 isoform, which decreased during cell damage and increased during cell proliferation. The 'locally acting' IGF1 was more active than the 'circulating' isoform in protecting cholangiocytes from GCDC-induced cytotoxicity. These findings indicate that, besides muscle and neural tissues, also in liver cells the 'locally acting' IGF1 isoform is important in modulating response to damage.

Laboratory Investigation (2008) 88, 986-994; doi:10.1038/labinvest.2008.63; published online 7 July 2008

KEYWORDS: bile salts; cholangiocytes; cholestasis; hepatocytes; IGF1

Insulin-like growth factor 1 (IGF1) is a circulating peptide hormone and locally acting growth factor with endocrine, paracrine and autocrine functions. ${ }^{1-4}$ The liver is the main source of circulating IGF1. ${ }^{1-4}$ The IGF1 produced by the liver is under control of GH (growth hormone) which, by acting on specific receptors, induces the synthesis and release of IGF1. ${ }^{1-4}$ Some evidence shows that signaling activated by IGF1 and IGF1 receptor (IGF1-R) is important in cell survival and prevention of apoptotic cell death and this was documented in different cell types (osteoblasts, ${ }^{5}$ myeloma cells, ${ }^{6}$ cardiac myoblasts, ${ }^{7}$ neuroblastoma cells, ${ }^{8}$ and different epithelia ${ }^{9}$ ). The cellular effects of IGFI are mediated through binding to the IGF1-R although IGF binding proteins may modulate the action of IGF1 controlling the amount of free IGF1 that can bind to its receptor. ${ }^{1-4,10}$ Binding of IGF1 to its receptor induces the stimulation of tyrosine kinase activity, autophosphorylation of tyrosine residues and other sites in the receptor and associated substrate proteins which, in turn, activate downstream signaling including the PI3K/AKT pathway, by which IGF1 prevents apoptosis and favors cell survival. ${ }^{1-4,10}$

Recently, a number of different studies have focused on the identification of different IGF1 isoforms and on the

${ }^{1}$ Department of Clinical Medicine, Division of Gastroenterology, University of Rome 'La Sapienza', Rome, Italy; ${ }^{2}$ Department of Clinical Medicine, Division of Gastroenterology, University of Rome 'La Sapienza', Polo Pontino, Latina, Italy and ${ }^{3}$ Department of Internal Medicine and System Biology and Translational Medicine, Scott \& White Hospital, Texas A\&M University System Health Science Center College Medicine, and Central Veterans Health Care, Temple, TX, USA

Correspondence: Professor D Alvaro, MD, Department of Clinical Medicine, Division of Gastroenterology, University of Rome 'La Sapienza', Polo Pontino, Via R Rossellini 51, 00137 Rome, Italy.

E-mail: domenico.alvaro@uniroma1

Received 23 December 2007; revised 21 April 2008; accepted 04 May 2008 
evaluation of their functional role. ${ }^{11-16}$ Thus, a 'locally acting' IGF1 isoform has been recently identified in the skeletal muscle and neural tissues where it accelerates injury repair by modulating all the cellular processes (resistance against apoptosis, cellular proliferation, recruitment of resident stem cells, neoangiogenesis etc) underlying the reparative process. ${ }^{11-16}$ In all these processes, the 'locally acting' is much more active than the 'circulating' IGF1 isoform. As a consequence, strategies aimed to enhance the expression of 'locally acting' IGF1 isoform are under investigation as a therapeutic option for degenerative-dystrophic diseases of neural and muscle tissues and, indeed, experimental evidence suggests potential benefits. ${ }^{17-26}$

Although the liver is the main organ producing and secreting IGF1, no information exists on the expression and function of the different IGF1 isoforms. We have recently shown in experimental studies that the IGF1 system and its main signaling transduction pathway (PI3kinase/Akt) are activated and drive cholangiocyte proliferation and resistance against apoptosis in obstructive cholestasis induced by bile duct ligation (BDL) and in determining the in vitro resistance of hepatocytes and cholangiocytes against the cytotoxic effect of hydrophobic bile salts (BS) ${ }^{27,28}$ By continuing on the same topic, the aims of our study were to identify IGF1 isoforms in rat hepatocytes and cholangiocytes and to evaluate their differential involvement in cell proliferation or damage induced by experimental cholestasis.

\section{MATERIALS AND METHODS}

Male Wistar rats (125-150 g) were purchased from Charles River Italia (Calco, Italy) and fed ad libitum in a light- and temperature-controlled environment. The study protocols were in compliance with our institution's guidelines. Reagents were purchased from Sigma-Aldrich Chemical Co. (St Louis, MO, USA) unless otherwise indicated. Media and additives for cell culture were obtained from Gibco (BRL, Invitrogen Corporation) unless otherwise indicated. BDL was performed as previously described ${ }^{27,29}$ and hepatocytes or cholangiocytes were isolated after $3 \mathrm{~h}$ or 1 week of BDL.

In the sham-operated rats, abdominal incision was made without a ligation.

\section{Isolation and Treatment of Cholangiocytes and Hepatocytes}

Cholangiocytes were isolated by immunomagnetic separation as previously described ${ }^{27,29}$ with a viability $>90 \%$ (trypan blue exclusion). The purity of cholangiocyte preparations was assessed by $\gamma$-glutamyltransferase-positive staining ( $100 \%$ of isolated cells) and by the negativity of contaminant cell markers tested as previously described. ${ }^{29}$ Hepatocytes were isolated, with a purity of $98 \%$ and a viability $>90 \%$ (trypan blue exclusion) as previously described. ${ }^{27,29}$

Cholangiocytes were cultured in $3 \mathrm{ml}$ of DMEM-F12 medium and hepatocytes were cultured in $3 \mathrm{ml}$ of $\alpha$-MEM medium. Media were added with $300 \mu \mathrm{l}$ nonessential MEM,
MEMvit, PenStrep, and L-Glutamine, $75 \mu$ l gentamicin and $25 \mu \mathrm{l}$ trypsin inhibitor. In selected experiments, hepatocytes or cholangiocytes were incubated for $3 \mathrm{~h}$, in the absence of serum and growth factors, with glycochenodeoxycholate (GCDC) $(100 \mu \mathrm{M}, 2 \mathrm{mM})$ and the IGF1 isoforms evaluated as described above.

\section{Sample Storage and RNA Preparation}

A $30 \mathrm{mg}$ piece of dissected tissue was immediately submerged in RNAlater stabilization solution (Ambion Inc., Austn, TX, USA). This sample was left $10 \mathrm{~min}$ at room temperature. Then, it was stored at $-20^{\circ} \mathrm{C}$ until RNA extraction. The tissue was removed from RNAlater and transferred into a clean Eppendorf tube where the total RNA was extracted by a silica membrane spin column procedure using the Nucleo Spin RNAII extraction kit (Macherey-Nagel, Düren, Germany). The isolated RNA was eluted in $50 \mu \mathrm{l}$ of RNasefree water.

RNA quality and quantity was evaluated by the RNA 6000 Nano LabChip kit with the Agilent 2100 Bioanalyzer (Agilent Technologies, Waldbronn, Germany).

\section{Reverse Transcription}

An amount of $2.5 \mu \mathrm{g}$ of total RNA was used for the RT reaction primed by the oligo $(\mathrm{dT})_{15}$. This was conducted in a $\mu \mathrm{l}$ volume with a genetically engineered version of the M-MuLV reverse transcriptase (Expand Reverse Trancriptase, Roche Diagnostics GmbH, Mannheim, Germany) according to the manufacturer's directions. The quality of cDNA produced, ie the length of the transcript and the lack of DNA contamination, was tested by PCR with the RNA/cDNA Inspector kit (Sigma-Aldrich) and the DNA1000 LabChip kit with the Agilent 2100 BioAnalyzer as described..$^{30,31}$

\section{Gene Expression}

The primers for amplifying the different transcripts of the IGF1 murine gene were designed with a commercial software (DNASIS, Ver. 2.5-Hitachi Software Engineering Co., France) using the mRNA sequences reported in a public database (http://www.ncbi.nlm.nih.gov/Entrez/). The oligo sequences were also submitted to a BLAST search (http:// www.ncbi.nlm.nih.gov/blast/) in order to verify the lack of annealing with incorrect targets. Finally, each primer pair was tested under standard PCR amplification conditions with a cDNA template from liver of control animals and the Bioanalyzer in order to verify the formation of the correct amplification products (not shown).

The primer pairs for amplifying three different types of IGF1 transcripts (ie the total of IGF1 messengers, the circulating and the locally acting IGF1 species) and the $\beta$-actin, used as the endogenous reference gene, are reported in Table 1.

The different types of messengers were determined by real-time PCR using the MX3000P quantitative PCR system (Stratagene, La Jolla, CA, USA). Amplifications were 


\begin{tabular}{|c|c|c|c|c|c|}
\hline Name & Primer sequence amplicon $\left(5^{\prime} \rightarrow 3^{\prime}\right)$ & Length (nt) & Gene target & Amplified size (bp) & Species \\
\hline FEX3 & CTCTTCAGTTCGTGTGTGGACCA & 23 & Exon 3 & 219 & Total IGF1 \\
\hline REX4 & TCTGAGTCTTGGGCATGTCAGTG & 23 & Exon 4 & & \\
\hline FEX1 & CCTGCGCAATCGAAATAAAGTCC & 23 & Exon 1 & 182 & X06108 \\
\hline REX1 & TTCAAGAAGTCACAGAGGCAGATC & 24 & Exon 1 & & 'Locally acting' \\
\hline FBACT & TGAAGATCAAGATCATTGCTCCTCC & 25 & Exon 5 & 154 & $\beta$-Actin \\
\hline RBACT & CTAGAAGCATTTGCGGTGGACGATG & 25 & Exon 6 & & NM_001101 \\
\hline
\end{tabular}

The total IGF1 determination included all the known transcripts of the gene. The NM_178866 and X06107 messengers reported by the Entrez database encoded the hepatic protein sequence NP_849197 and the extrahepatic protein sequences CAA29480 and CAA29481, respectively.

conducted into a total volume of $25 \mu \mathrm{l}$, with $1.0 \mu \mathrm{l}$ of cDNA template, $12.5 \mu \mathrm{l}$ of $2 \times$ Brilliant SYBR Green QPCR Master Mix (Stratagene), 3 pmoles each of upstream and downstream primer for the gene analyzed, and $0.3 \mu \mathrm{l}$ of diluted reference dye (ROX at a final concentration $30 \mathrm{nM})$. All real-time PCR amplifications were conducted with the following cycling program: $10 \mathrm{~min}$ at $95^{\circ} \mathrm{C}$ followed by 40 cycles $\left(30 \mathrm{~s}\right.$ at $95^{\circ} \mathrm{C}, 30 \mathrm{~s}$ at $57^{\circ} \mathrm{C}, 1 \mathrm{~min}$ at $72^{\circ} \mathrm{C}$ ). The fluorescence detection was performed during the extension step of each cycle.

The copy numbers of the different messengers amplified by each primer pair reported in Table 1 were determined by comparing the threshold cycle $\left(C_{\mathrm{t}}\right)$ values measured in a specific cDNA preparation with the calibration curves $C_{\mathrm{t}}$ vs. template amount obtained with standard solutions of the messengers. These standard solutions were prepared by amplifying control liver cDNAs with the above described primer pairs and the Platinum Taq Polymerase (Invitrogen srl, S Giuliano Milanese, Italy). Thereafter, each type of amplification product was purified by silica gel cartridges (GenElut, Supelco Inc., Bellefonte, PA, USA) and finally controlled, both qualitatively and quantitatively, by microchip electrophoresis with the Agilent Bioanalyzer. These calibrated solutions were used for preparing the scalar dilutions (within the range $10^{2}-10^{7}$ per $\mu$ l copies of the target) required for the real-time PCR determinations. The software used in the MX3000P instrument allowed verifying both linearity and efficiency of the amplification curve. Also, it turned the normalized $C_{\mathrm{t}}$ value into a copy number of each target. Each sample was analyzed in triplicate. The copy numbers of local and circulating species were normalized in each cDNA sample by calculating their percentage with respect to the copy number of total IGF1. The missing complement to $100 \%$ was attributed to minor messenger species.

Sequence analyses of IGF1 isoforms in rat liver cells showed a complete homology with the sequence reported in the Entrez genomic database (http://www.ncbi.nlm.nih.gov/ Entrez/).

\section{SILENCING}

For IGF1 silencing, isolated cholangiocytes were cultured overnight in DMEM-F12 medium added with $300 \mu$ nonessential MEM, MEMvit, PenStrep, L-glutammine, $75 \mu \mathrm{l}$ gentamicin, $25 \mu \mathrm{l}$ trypsin inhibitor, fetal calf serum $(1 \mathrm{ml} /$ $30 \mathrm{ml}$ medium), the specific SiRNA $(1 \mu \mathrm{l} / \mathrm{ml}$ medium) in ACQUA milliQ (stock $50 \mu \mathrm{M}$ ) and directed against exon 3 of IGF1 mRNA (Silencer ${ }^{\mathrm{TM}}$ Pre-Designed siRNA; annealed, $20 \mathrm{nmol}$ of standard purity) and the lipidic vector (Si-Port NeoFX; $1 \mu \mathrm{l} / \mathrm{ml}$ medium; Ambion Europe, United Kingdom). After overnight incubation with SiRNA for IGF1 and the lipidic vector, cholangiocytes were treated for $3 \mathrm{~h}$ with $2 \mathrm{mM}$ GCDC or TCDC and mRNA for IGF1 isoforms, apoptosis and proliferation evaluated as described. To exclude nonspecific effects of IGF1-SiRNA, scrambled SiRNA of the same size (silencer negative control) was also used in selected experiments. For total IGF1 silencing, isolated cholangiocytes were treated overnight, as described in the data sheet, with $50 \mu \mathrm{M}$ of small interfering RNA (plus lipid carrier), against exon number 3 of total mRNA for the IGF1 protein (catalog no. 16704, Silencer ${ }^{\mathrm{TM}}$ Pre-Designed siRNA; annealed, $20 \mathrm{nMol}$ of standard purity; si PORT ${ }^{\mathrm{TM}}$ neoFX ${ }^{\mathrm{TM}}$ AMBION). For silencing specific IGF1 isoforms, following the AMBION web site direction, we designed siRNA against the specific mRNA of 'locally acting' and 'circulating' IGF1 as follows: circulating IGF1: sense: GGGAAAGGAGCUGCCACUUGtt; antisense: CAAGUGGCAGCUCCUUCCCtt; 'locally acting' IGF1: sense: GGAAGCUGCAAAGGAGAAGtt; antisense: CUUCUCCUUUGCAGCUUCCtt. Cells were treated, as above, with $50 \mu \mathrm{M}$ of SiRNA plus lipid carrier. After $14-16 \mathrm{~h}$ of incubation with specific SiRNA, cells were treated for $3 \mathrm{~h}$ with GCDC $2 \mathrm{mM}$ and apoptosis or proliferation evaluated as described. In control experiments, cholangiocytes were incubated with scrambled SiRNA of the same size.

\section{Proliferation and Apoptosis}

Cell proliferation was assessed, as previously described, by both $\left[{ }^{3} \mathrm{H}\right]$-thymidine incorporation into DNA and western 
blot for PCNA. ${ }^{27-29}$ For $\left[{ }^{3} \mathrm{H}\right]$-thymidine, methyl $\left[{ }^{3} \mathrm{H}\right]$ thymidine $(25 \mathrm{Ci} / \mathrm{mmol}$; Amersham Biosciences Europe $\mathrm{GmbH}$, Italy) was added into the culture medium $(1 \mu \mathrm{Ci} / \mathrm{ml})$ and the incubation with $\left[{ }^{3} \mathrm{H}\right]$-thymidine continued for $2 \mathrm{~h}$, corresponding to the last $2 \mathrm{~h}$ of treatment with GCDC. Cell extraction and radioactivity measurement were performed as described. $^{27-29}$

Apoptosis was evaluated by both caspase 3 activity and Annexin V staining. For caspase 3 we used a colorimetric assay kit (Sigma-Aldrich), based on the hydrolysis of the peptide substrate acetyl-Asp-Glu-Val-Asp p-nitroanilide (Ac-DEVD-pNA) by caspase 3, resulting in the release of the $p$-nitroaniline (pNA). For this assay, cells were lyzed in the appropriate lysis buffer provided by the vendor $(50 \mathrm{mM}$ HEPES, pH 7.4, $5 \mathrm{mM}$ CHAPS, $5 \mathrm{mM}$ DTT). The concentration of the pNA released from the substrate is calculated from the absorbance values at $405 \mathrm{~nm}$. Caspase 3 activity resulting from the measured concentration of pNA was expressed as percentage changes with respect to controls. Annexin V staining, a specific marker of early-stage apoptosis, ${ }^{32}$ was carried out, as previously described, ${ }^{28}$ by using a commercial kit (Boehringer Mannheim GmBH, Mannheim, Germany) according to the manufacturer's instructions. Findings were expressed as the number of annexin V-positive cells per 100 counted cholangiocytes (at least 500 cholangiocytes counted for each determination).

\section{Western Blot Analyses}

For western blot analysis, after each treatment, cells were harvested, washed with PBS and homogenized by sonicating in lysis buffer $(15 \mathrm{mM}$ Tris- $\mathrm{HCl}, \mathrm{pH} 7.4,5 \mathrm{mM}$ EDTA, $100 \mathrm{mM} \mathrm{NaCl}$, Igepal 1\%, $2 \mathrm{mM}$ phenyl methyl sulfonyl fluoride, $2 \mathrm{mM}$ benzamidine and $1 \%$ aprotinin) on ice for $30-60 \mathrm{~s}$. After centrifugation at $14000 \mathrm{~g}$ for $60 \mathrm{~s}$ at $4^{\circ} \mathrm{C}$, the supernatant was recovered and protein concentration was determined with the Bio-Rad Protein Assay-Dye Reagent (Bio-Rad Laboratories GmbH, Germany). Cell extracts $(20 \mu \mathrm{g})$ were diluted in $6 \times$ Laemly sample buffer $(100 \mathrm{mM}$ Tris-HCl, pH 6.8, 20\% glycerol, 4\% SDS, 5\% 2-mercaptoethanol, $0.1 \%$ bromophenol blue) and resolved by $10 \%$ SDS-polyacrylamide gel electrophoresis. Western blotting was performed as described ${ }^{10-15}$ by using the following primary antibodies (Santa Cruz Biotechnology, Santa Cruz, CA, USA): (1) anti-PCNA, specific mouse monoclonal antibody (1:300 dilution) and (2) anti-IGF1, rabbit polyclonal antibody (1:100 dilution).

The carrier of $17 \beta$-estradiol (ie DMSO) and of Ici182,780 (ie ethanol) showed no effect (1:10000 dilution) on MTS proliferation assay $(n=6)$ nor on $\left[{ }^{3} \mathrm{H}\right]$-thymidine incorporation into DNA $(n=6)$ of LCDE cells compared with controls in the absence of these two additives.

\section{Statistical Analysis}

Data are presented as arithmetic mean \pm s.e.m. Statistical analysis was conducted using the paired or unpaired
Table 2 Percent distribution of mRNA for IGF1 isoforms in rat hepatocytes and cholangiocytes

\begin{tabular}{lcc}
\hline & Hepatocytes & Cholangiocytes \\
\hline NM_178866 'circulating' & $52.8 \pm 5.4$ & $52.6 \pm 5.8$ \\
XO6108 'locally acting' & $44.8 \pm 4.9$ & $43.9 \pm 4.6$ \\
Other species & $2.4 \pm 1.03$ & $3.50 \pm 1.10$ \\
\hline
\end{tabular}

Mean \pm s.e. from six independent experiments.

Student's $t$-test as appropriate or the analysis of the variance (ANOVA) when multiple comparisons were performed.

\section{RESULTS}

Isolated rat hepatocytes and cholangiocytes expressed similar proportions of the two major IGF1 isoforms (ie 'circulating' and 'locally acting') plus relative rare messengers classified as 'other species' (Table 2). In particular, the sequence amplified by the FEX1-REX1 primer pair (182 bp) corresponded (sequence analysis) to the 'locally acting' IGF1 isoform (XO6108) and represented approximately $44 \%$ of the total IGF1 mRNA in both hepatocytes and cholangiocytes (Table 2). The sequence amplified by the FEX2-REX3 primer (121 bp) corresponded (sequence analysis) to the secretory and 'circulating' IGF1 isoform (NM_178866) and represented approximately $53 \%$ of the total IGF1 mRNA (Table 2). The other isoforms represented less than 3.5\% of total IGF1 mRNA (Table 2).

In sham-operated controls, the normalized value of total IGF1 mRNA (ie the ratio of copy numbers total IGF1/ $\beta$-actin) was significantly higher in normal rat hepatocytes than cholangiocytes (Tables 3 and 4; $P<0.05$ ). Also mRNAs of both 'locally acting' (XO6108) and 'circulating' IGF1 isoforms (NM_178866) were significantly higher in hepatocytes (Tables 3 and $4 ; P<0.05$ ). After $3 \mathrm{~h}$ of BDL, total IGF1 decreased more than $50 \%$ in hepatocytes with respect to $3 \mathrm{~h}$ sham-operated controls (Table 3 ) and this was caused by a $75 \%$ decrease of 'locally acting' (XO6108) isoform, whereas the circulating IGF1 isoform (NM_178866) was not significantly modified (Table 3 ). In cholangiocytes, instead, total IGF1 mRNA and the two isoforms NM_178866 and XO6108 remained almost stable after $3 \mathrm{~h}$ of $\mathrm{BDL}$ with respect to cholangiocytes isolated from sham-operated controls (Table 4). After 1 week of BDL, mRNAs for total IGF1, NM_178866 and XO6108 isoforms in hepatocytes further declined with a relatively more prominent decrease of the 'locally acting' XO6108 (81\% decrease) with respect to the circulating (44\% decrease) isoform (Table 3$)$. In cholangiocytes, in contrast, after 1 week of BDL, total IGF1 mRNA and the two isoforms NM_178866 and XO6108 were markedly increased over sham-operated controls (Table 4; $P<0.01$ ) with a major contribution of the circulating ( $1215 \%$ increase) 
Table 3 Normalized mRNA levels of total IGF1 and its major isoforms (ie ratios of copy numbers of IGF1 messenger species/ $\beta$-actin) in hepatocytes

\begin{tabular}{lccc}
\hline Hepatocytes & Total & $\begin{array}{c}\text { NM_178866 } \\
\text { 'circulating' }\end{array}$ & $\begin{array}{c}\text { XO6108 } \\
\text { 'locally acting' }\end{array}$ \\
\hline Sham-operated 3 $\mathrm{h}$ & $2.22 \pm 0.19$ & $1.19 \pm 0.20$ & $1.05 \pm 0.12$ \\
BDL 3 h & $1.03 \pm 0.14^{*}$ & $0.70 \pm 0.08$ & $0.26 \pm 0.03^{*}$ \\
Sham-operated 1 week & $2.12 \pm 0.20$ & $1.07 \pm 0.13$ & $0.99 \pm 0.10$ \\
BDL 1 week & $0.82 \pm 0.09^{*}$ & $0.60 \pm 0.07^{*}$ & $0.18 \pm 0.02^{*}$
\end{tabular}

Mean \pm s.e. from six independent experiments.

${ }^{*} P<0.05$ vs normal rat.

Table 4 Normalized mRNA levels of total IGF1 and its major isoforms (ie ratios of copy numbers of IGF1 messenger species/ $\beta$-actin) in cholangiocytes

\begin{tabular}{lccc}
\hline Cholangiocytes & Total & $\begin{array}{c}\text { NM_178866 } \\
\text { 'circulating' }\end{array}$ & $\begin{array}{c}\text { XO6108 } \\
\text { 'locally acting' }\end{array}$ \\
\hline Sham-operated 3 $\mathrm{h}$ & $1.17 \pm 0.15$ & $0.61 \pm 0.10$ & $0.56 \pm 0.08$ \\
BDL 3 h & $1.77 \pm 0.23$ & $0.93 \pm 0.09$ & $0.79 \pm 0.08$ \\
Sham-operated 1 week & $1.20 \pm 0.17$ & $0.60 \pm 0.10$ & $0.53 \pm 0.07$ \\
BDL 1 week & $11.45 \pm 1.82^{*}$ & $7.29 \pm 0.85^{*}$ & $3.89 \pm 0.44^{*}$
\end{tabular}

Mean \pm s.e. from six independent experiments.

${ }^{*} P<0.05$ vs sham-operated.

with respect to the 'locally acting' (733\% increase) isoform (Table 4).

Similar to what had been observed after $3 \mathrm{~h}$ of BDL, the in vitro incubation of rat hepatocytes with $100 \mu \mathrm{M}$ GCDC determined a $310 \%$ decrease of the 'locally acting' XO6108 isoform and a 60\% decrease of the 'circulating' NM_178866 isoform. In cholangiocytes, in contrast, incubation with $2 \mathrm{mM}$ GCDC for $3 \mathrm{~h}$ failed to induce significant changes of IGF1 isoform mRNA (Figure 1).

\section{Effect of Specific IGF1 Isoform Silencing on GCDC- Induced Apoptosis or Proliferation in Isolated Rat Cholangiocytes}

As evaluated by western blot analysis, overnight incubation with SiRNA for the 'locally acting' or 'circulating' IGF1 isoform induced an approximate $45 \%$ decrease of total IGF1 protein level in cholangiocytes with respect to controls incubated with scrambled SiRNA (Figure 2; $n=3, P<0.01$ ).

To evaluate the effect of specific IGF1 isoform silencing on GCDC-induced changes in apoptosis/proliferation, isolated rat cholangiocytes were incubated overnight with specific SiRNAs for the 'locally acting' or 'circulating' IGF1 isoforms. Thereafter, the effects of $2 \mathrm{mM}$ GCDC ( $3 \mathrm{~h}$ incubation) were evaluated. Figure 1 shows how the overnight incubation with SiRNA for 'locally acting' or 'circulating' IGF1 isoforms

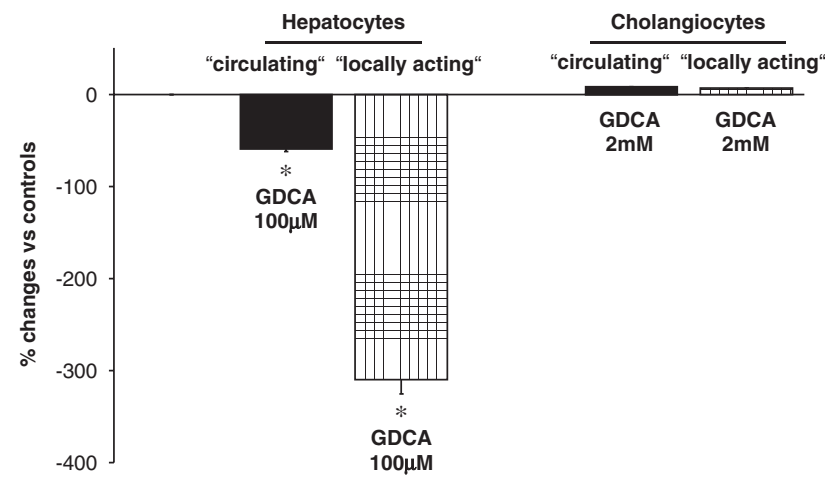

Figure 1 Effect of GCDC on the expression of mRNAs for 'locally acting' and 'circulating' IGF1 isoforms in isolated rat hepatocytes and cholangiocytes. Isolated rat hepatocytes and cholangiocytes were incubated for $3 \mathrm{~h}$ with $100 \mu \mathrm{M}$ or $2 \mathrm{mM} \mathrm{GCDC}$ respectively. The expression of 'locally acting' and 'circulating' IGF1 isoform was evaluated by real-time PCR ( $n$ copies/ $\beta$-actin) and expressed as percent changes vs controls. In hepatocytes, GCDC determined a 310\% decrease of the local X06108 isoform and a $60 \%$ decrease of circulating NM_178866 isoform. In cholangiocytes, however, incubation with $2 \mathrm{mM} \mathrm{GCDC}$ for $3 \mathrm{~h}$ failed to induce significant changes of IGF1 isoform mRNA. Mean \pm s.e. from five independent experiments. ${ }^{\star} P<0.01$ vs controls.

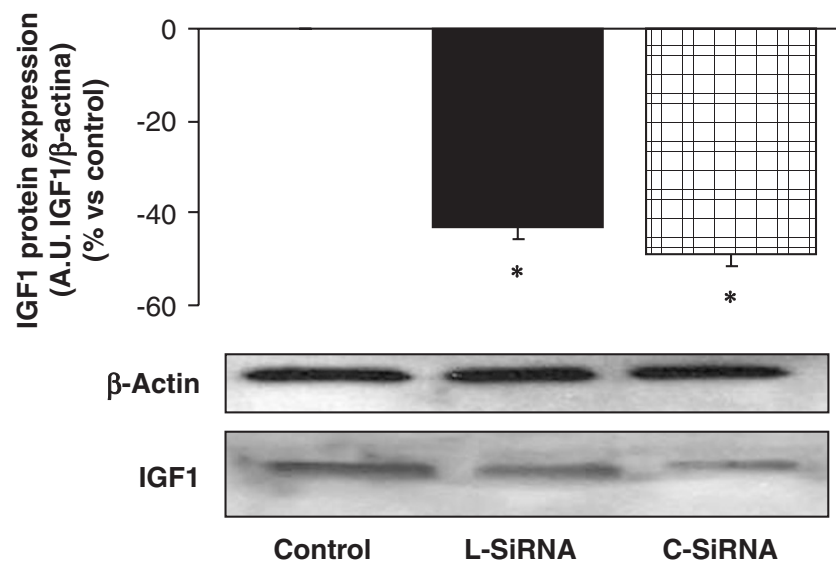

Figure 2 Effect of IGF1 isoform selective silencing on the protein expression (western blot) of total IGF1 in isolated rat cholangiocytes. Western blot analysis of total IGF1 in cholangiocytes incubated overnight with SiRNA (see 'Materials and Methods') specific for 'locally acting' (L-SiRNA) or 'circulating' IGF1 (C-SiRNA) isoforms. The IGF1 protein level was expressed (Prot Expr) as arbitrary densitometric units (AU) normalized to $\beta$-actin expression (ie tested protein/ $\beta$-actin) and reported as percentage change with respect to controls. Protein expression of $\beta$-actin was similar between different experiments. The overnight incubation with SiRNA for 'locally acting' or 'circulating' IGF1 isoform induced a significant decrease of total IGF1 with respect to controls incubated with scrambled SiRNA of the same size. Data are expressed as mean \pm s.e. from three independent experiments. ${ }^{\star} P<0.01$ vs controls.

induced an inhibition of proliferation (decreased PCNA expression and $\left[{ }^{3} \mathrm{H}\right]$-thymidine incorporation) that was significantly more pronounced for the 'locally acting' with respect to the 'circulating' isoform $(P<0.05, n=6$; Figures 3a and $\mathrm{b})$. When isolated control cholangiocytes, incubated 


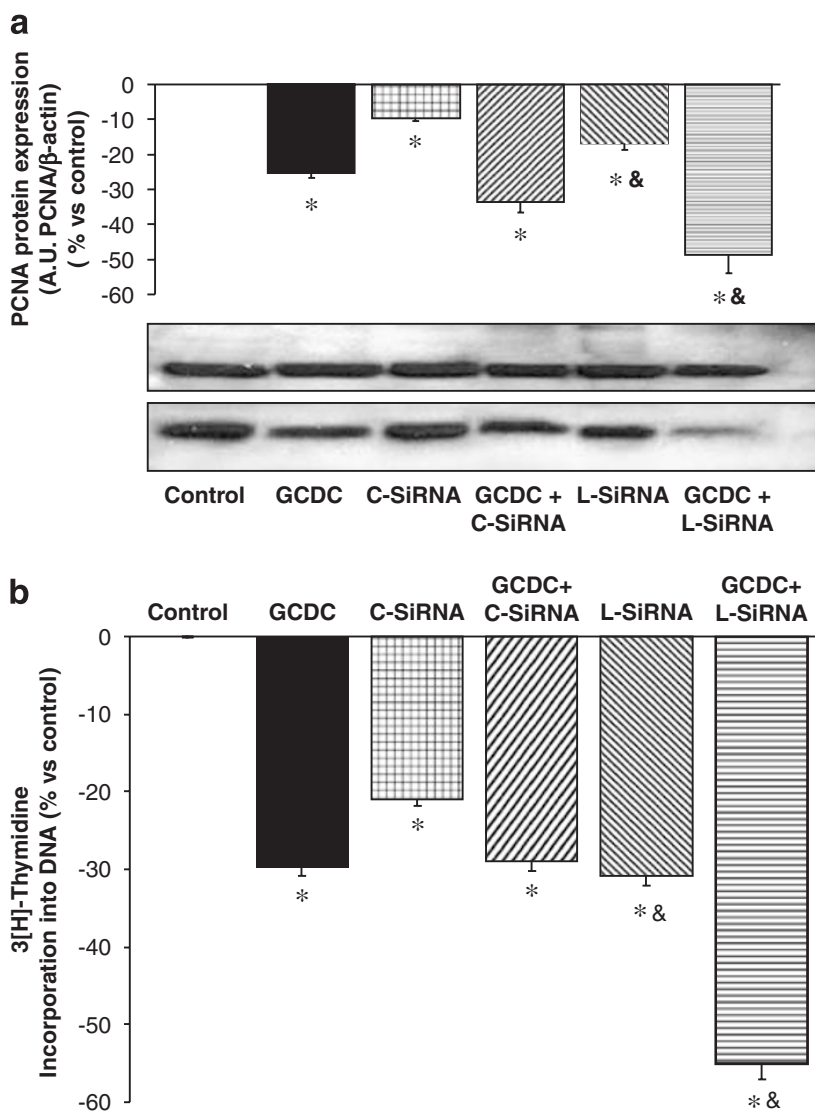

Figure 3 Effect of IGF1 isoform selective silencing on GCDC-induced PCNA expression (western blot) and $\left[{ }^{3} \mathrm{H}\right]$-thymidine incorporation into DNA of isolated cholangiocytes. (a) Western blot analysis of PCNA in cholangiocytes incubated overnight with SiRNA (see Materials and Methods) specific for 'locally acting' (L-SiRNA) or 'circulating' (C-SiRNA) IGF1 isoforms and then with $2 \mathrm{mM} \mathrm{GCDC}$ for $3 \mathrm{~h}$. The PCNA protein was expressed (Prot Expr) as arbitrary densitometric units (AU) normalized to $\beta$-actin expression (ie tested protein/ $\beta$-actin) and reported as percentage change with respect to controls. Protein expression of $\beta$-actin was similar between different experiments. The overnight incubation with SiRNA for 'locally acting' or 'circulating' IGF1 isoform induced a decrease of PCNA (inhibition of proliferation) protein expression which was significantly more pronounced for the 'locally acting' isoform. Incubation with $2 \mathrm{mM} \mathrm{GCDC}$ decreases PCNA protein expression into a higher extent in cholangiocytes silenced for the 'locally acting' IGF1 isoform with respect to 'circulating' IGF1 isoform. Data are mean \pm s.e. of six independent experiments. ${ }^{\star} P<0.05$ vs control. ${ }^{\&} P<0.05$ vs C-SiRNA or C-SiRNA + GCDC. (b) $\left[{ }^{3} \mathrm{H}\right]-$ Thymidine incorporation into DNA. In the same experimental conditions described in $(\mathbf{a}),\left[{ }^{3} \mathrm{H}\right]$-thymidine was added into the culture medium $(1 \mu \mathrm{Ci} / \mathrm{ml})$ for the last $2 \mathrm{~h}$ of each treatment. The overnight incubation with SIRNA for local and circulating IGF1 isoforms induced a decrease of $\left[{ }^{3} \mathrm{H}\right]$-thymidine incorporation into DNA (inhibition of proliferation) that was significantly more pronounced for the 'locally acting' isoform. Incubation with $2 \mathrm{mM} \mathrm{GCDC}$ decrease $\left.{ }^{3} \mathrm{H}\right]$-thymidine incorporation into DNA into a higher extent in cholangiocytes silenced for the 'locally acting' IGF1 isoform compared with 'circulating' IGF1 isoform. Data are mean \pm s.e. of $n=6$. ${ }^{*} P<0.05$ vs control; ${ }^{\&} P<0.05$ vs C-SiRNA or C-SiRNA + GCDC.

overnight with scrambled IGF1 SRNA, were exposed to $2 \mathrm{mM}$ GCDC, proliferation was inhibited by approximately $25 \%$ (Figures $3 \mathrm{a}$ and $\mathrm{b} ; n=6$ ). The GCDC-induced inhibition of proliferation (decreased PCNA and $\left[{ }^{3} \mathrm{H}\right]$-thymidine incorporation) was significantly more pronounced $(P<0.05$, $n=6)$ in cholangiocytes silenced for the 'locally acting' IGF1 isoform $(-33 \%, \mathrm{PCNA})$ compared with the 'circulating' IGF1 isoform ( $-48 \%$, PCNA) (Figure 3$)$.

As far as GCDC-induced apoptosis is concerned, overnight incubation with SiRNA for 'locally acting' or 'circulating' IGF1 isoforms, induced an increase of apoptosis (caspase 3) that was significantly higher for the 'locally acting' isoform $(P<0.05, n=6$; Figure 4a). When control-isolated cholangiocytes incubated overnight with scrambled IGF1 SRNA, were exposed to $2 \mathrm{mM}$ GCDC, apoptosis (caspase 3) was enhanced by $37 \%$ (Figure $4 \mathrm{a} ; n=6$ ). The GCDC-induced activation of apoptosis was slightly enhanced in cholangiocytes silenced for the 'circulating' IGF1 isoform (47\%, $P<0.05$ vs GCDC alone, $n=6$ ) but markedly increased in cholangiocytes silenced for the 'locally acting' IGF1 isoform (83\%, $n=6$; Figure 4a). Results obtained by evaluating caspase 3 activity were confirmed by counting the number of annexin V-positive cholangiocytes. In fact, overnight incubation with SIRNA for 'locally acting' and 'circulating' IGF1 isoforms induced an increase in the number of annexin V-positive cholangiocytes, which was significantly higher $(P<0.05, n=10$; Figure $4 \mathrm{~b})$ for the 'locally acting' isoform. GCDC induced an increase of annexin $\mathrm{V}$ positivity in cholangiocytes silenced for the 'locally acting' IGF1 isoform which was markedly higher with respect to cholangiocytes silenced for the 'circulating' IGF1 isoform $(P<0.05, n=10$; Figure $4 b$ ).

These findings altogether indicate that the 'locally acting' IGF1 isoform is more active than the 'circulating' isoform in promoting a defensive mechanism against CCDC-induced inhibition of proliferation and activation of apoptosis in isolated rat cholangiocytes.

\section{DISCUSSION}

The main findings of this study demonstrate that: (1) mRNAs for either 'locally acting' and 'circulating' IGF1 isoforms are expressed both in hepatocytes and cholangiocytes; (2) after $3 \mathrm{~h}$ of BDL, total IGF1 decrease more than $50 \%$ in hepatocytes mainly due to a $72 \%$ reduction of 'locally acting' (XO6108) isoform, whereas the circulating IGF1 isoform (NM_178866) was unchanged. In cholangiocytes, however, total IGF1 mRNA and the two isoforms remained almost stable after $3 \mathrm{~h}$ of BDL; (3) the effect of $3 \mathrm{~h}$ of BDL on IGF1 isoforms was reproduced in vitro by the incubation of hepatocytes and cholangiocytes with GCDC; (4) after 1 week of BDL, mRNAs for total IGF1, 'locally acting' and 'circulating' isoforms in hepatocytes further declined with a relatively more prominent decrease of the 'locally acting' isoform; (5) in cholangiocytes, in contrast, after 1 week of BDL, total IGF1 mRNA and the two isoforms were markedly increased; (6) selective silencing of IGF1 isoforms in isolated cholangiocytes enhanced the inhibitory effects of GCDC on proliferation and the induction of apoptosis with a more pronounced 


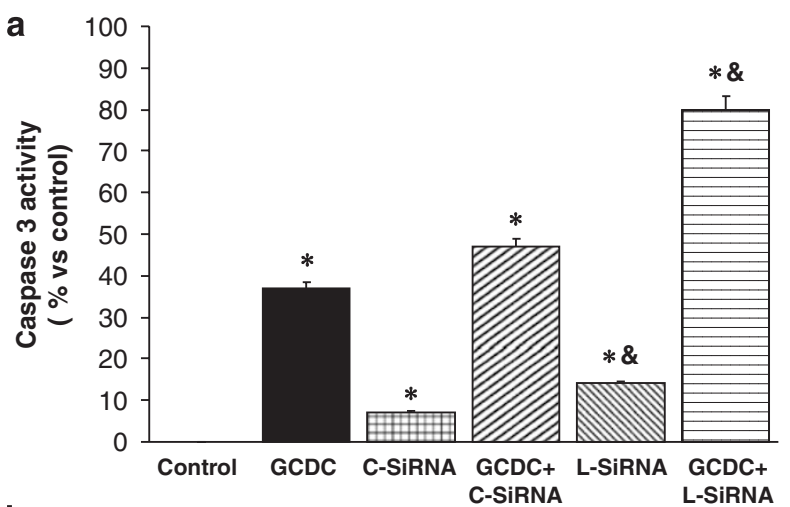

b

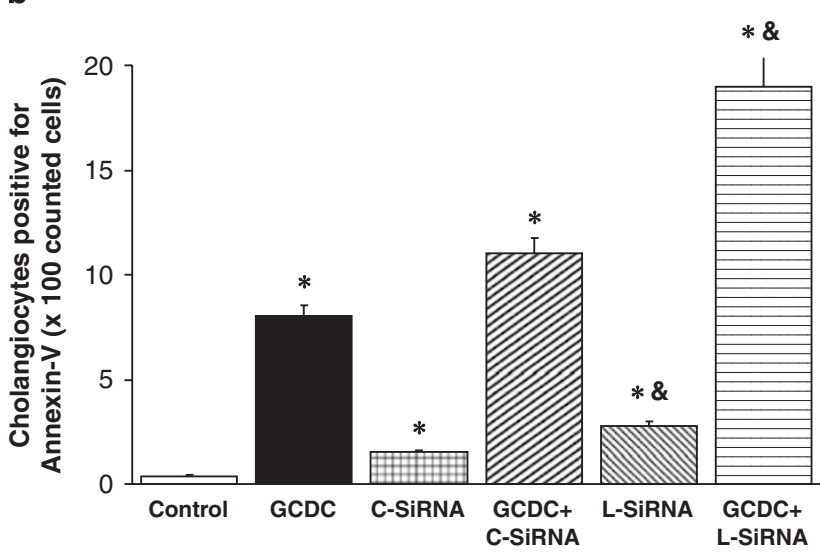

Figure 4 Effect of IGF1 isoform selective silencing on GCDC-induced apoptotis in isolated cholangiocytes. (a) Caspase 3 activity (\% increase with respect to controls) in cholangiocytes incubated overnight with SiRNA (see 'Materials and Methods') specific for 'locally acting' or 'circulating' IGF1 isoforms and then with $2 \mathrm{mM} \mathrm{GCDC}$ for $3 \mathrm{~h}$. Caspase 3 activity was expressed as percent changes with respect to controls. Overnight incubation with SIRNA for 'locally acting' and 'circulating' IGF1 isoforms induced an increase of apoptosis which was significantly higher for the 'locally acting' isoform. GCDC induced an increase of caspase 3 activity in cholangiocytes silenced for the 'locally acting' IGF1 isoform, which was markedly higher with respect to cholangiocytes silenced for the 'circulating' IGF1 isoform. Data are mean \pm s.e. of $n=6$. ${ }^{\star} P<0.05$ vs controls; ${ }^{\circledR} P<0.05$ vs C-SiRNA or C-SiRNA + GCDC. (b) Annexin V: overnight incubation with SIRNA for 'locally acting' and 'circulating' IGF1 isoforms induced an increase in the number of annexin V-positive cholangiocytes, which was significantly higher for the 'locally acting' isoform. GCDC induced an increase of annexin $V$ positivity in cholangiocytes silenced for the 'locally acting' IGF1 isoform, which was markedly higher with respect to cholangiocytes silenced for the 'circulating' IGF1 isoform. Data are mean \pm s.e. of $n=10$. ${ }^{\star} P<0.05$ vs controls; ${ }^{\circledR} P<0.05$ vs C-SiRNA or C-SiRNA + GCDC.

effect observed after silencing of the 'locally acting' than the 'circulating' isoform. These findings altogether indicate that, other than in muscle and neural tissues, the 'locally acting' IGF1 isoform may be important in modulating proliferation and resistance against cholestatic injury also in liver cells.

A bulk of recent literature deals with the identification of different IGF1 isoforms and on the evaluation of their functional role in different tissue. ${ }^{11,26}$ The IGF1 isoforms derive from alternative splicing of the primary trascripts of the gene (localized in 7q12-q13 of the murine genome). ${ }^{11,26}$ Current interest for the IGF1 isoforms derives from research in the fields of muscle and nervous system, which synthesize tissue-specific IGF1 isoforms acting only locally with autocrine/paracrine mechanisms and playing a major role in injury repair. ${ }^{11,26}$ The 'locally acting' IGF1 isoform, in fact, modulates all the cellular processes (apoptosis resistance, cellular proliferation, resident stem cell recruitment, neoangiogenesis, etc), underlying the reparative process. ${ }^{11,26}$ In addition, transgenic mice producing high levels of the locally acting' IGF1 isoform are extremely resistant to the injury and strategies of infusion of this isoform play a trophic effect, thus suggesting potential applications in degenerative and dystrophic pathologies of nervous and muscle tissue (amyotrophic lateral sclerosis, dementia, muscle dystrophies, dilatative cardiomiopathies, muscle degenerative diseases). ${ }^{16-22}$ These therapeutic strategies have already been applied successfully in experimental models of muscle and nerve damage, including dystrophic/degenerative muscle diseases, lateral amyotrophic sclerosis and experimental stroke. ${ }^{17-23}$ In fact, overexpression of IGF1 in muscle protects against age-related sarcopenia ${ }^{24}$ and similar findings have been obtained in retinal and bone tissue. ${ }^{25,26}$ In all these investigations, the 'locally acting' IGF1 isoform resulted 5-10 times more active than the 'circulating' or systemic IGF1 isoform that is secreted by the liver.

Although $90 \%$ of circulating IGF1 originates in the liver under GH control, ${ }^{1-4}$ nothing is known about the expression of the IGF1 isoforms in the hepatocytes and cholangiocytes. Experimental studies have been performed by focusing only on total IGF1. In cirrhotic rats, administration of low-dose recombinant IGF-I improved hepatocellular function, portal hypertension and liver fibrosis other than cirrhosis-related extrahepatic clinical manifestations by improving food efficiency, muscle and bone mass, gonadal and intestinal function and structure. ${ }^{33-36}$ Finally, a recent study indicates reversal of experimental cirrhosis induced by IGF1 administration in the rat. ${ }^{37}$ In the light of this experimental evidence, a first pilot clinical trial in a small number of cirrhotic patients showed increased serum albumin and improved energy metabolism as a result of IGF1 administration. ${ }^{38}$

With this background, we investigated the expression of IGF1 isoform mRNAs in isolated rat hepatocytes and cholangiocytes. Pure preparations of hepatocytes and cholangiocytes were used and the real-time PCR analyses showed the expression of at least three different isoforms. However, the 'circulating' and 'locally acting' isoforms altogether represented more than $95 \%$ of the total. Unfortunately investigation into the protein expression of the two major isoforms is not currently possible mainly because of the unavailability of specific antibodies for immunoblotting or immunohistochemistry. We next focused on these two isoforms and on their changes in the BDL model of experimental cholestasis where hepatocytes and cholangiocytes differently react to damage. The BDL experimental model of cholestasis has been widely investigated by a huge number of studies performed by us ${ }^{27-29,39}$ and other groups ${ }^{40-46}$ and 
the effects on hepatocytes and cholangiocytes accurately defined. We investigated two different time points after BDL; short-term $(3 \mathrm{~h}) \mathrm{BDL}$, where hepatocytes and cholangiocytes do not proliferate but are damaged by the increased bile pressure and accumulation of $\mathrm{BS},{ }^{43,44}$ and prolonged BDL (1 week) where hepatocytes underwent apoptotic damage with proliferation occurring in a minor percentage of cells, whereas, in contrast, cholangiocytes underwent massive and typical proliferation. ${ }^{27-29,39-46}$ Recent studies have demonstrated that few hours of BDL are sufficient to induce liver damage and to promote the increase in growth factor (defensive response). ${ }^{43,44}$ In addition, the present and our previous study ${ }^{28}$ indicated how, in vitro, hydrophobic BS induce, after only $3 \mathrm{~h}$, apoptotic damage and impairment of the IGF1 system in isolated hepatocytes and cholangiocytes. In this study, we demonstrated that after $3 \mathrm{~h}$ of BDL (but not after sham operation), total IGF1 and mainly the locally acting' isoform was significantly decreased in hepatocytes, whereas in cholangiocytes, in contrast, total IGF1 mRNA and the two isoforms remained almost stable. BS accumulation is currently considered the main mechanism of cell damage in obstructive cholestasis ${ }^{46}$ and, as a consequence, we investigated whether the effect of short-term BDL could have been reproduced by in vitro incubation of hepatocytes and cholangiocytes with GCDC, a main hydrophobic BS. Indeed, we showed almost similar changes of IGF1 isoforms after in vitro incubation with GCDC than after $3 \mathrm{~h}$ BDL. Therefore, it is conceivable that acute cholestatic damage induces impairment of the IGF1 system in hepatic cells which was, however, much more evident in hepatocytes than cholangiocytes. This is consistent with a protective role of the IGF1 system against the cytotoxic effect of hydrophobic BS and, in keeping, to this regard cholangiocytes are much more resistant than hepatocytes. ${ }^{28}$

After 1 week of BDL, while hepatocytes still showed apoptotic damage and proliferation occurred only in a minor percentage of cells, cholangiocytes markedly proliferate. ${ }^{27-29,39-49}$ Consistent with our hypothesis that the IGF system and mainly the 'locally acting' isoform is involved in modulating proliferation, mRNA for this isoform markedly decreased in hepatocytes whereas, the opposite was found in cholangiocytes in association with their typical proliferation.

In a previous in vitro study, we demonstrated that the IGF1 system is involved in defending hepatocytes and cholangiocytes against the cytotoxic effects of hydrophobic $\mathrm{BS}^{28} \mathrm{In}$ fact, in both rat hepatocytes and cholangiocytes, the IGF1-R blocker or silencing of total IGF1 markedly enhanced GCDCinduced apoptosis. In the present study, to further support findings obtained in BDL rats, the role of the 'locally acting' isoform in modulating cholangiocyte resistance against BS cytotoxicity was definitively investigated by using specific SiRNA able to induce a selective silencing of IGF1 isoforms. That this technique was really effective was demonstrated by the significant decrease of total IGF1 protein level. In our conditions, cholangiocytes silenced for the 'locally acting'
IGF1 isoform showed a higher sensitivity to the cytotoxic effects of GCDC, as the inhibitory effects of GCDC on proliferation and the induction of apoptosis was more pronounced with respect to the 'circulating' isoform. Interestingly, reduced PCNA in GCDC/SiRNA-treated cells appears to be equal to the effects of GCDC treatment alone plus the effect of SiRNA treatment alone suggesting an additive effect of the two compounds. Unfortunately, selective silencing IGF1 isoforms was not possible in hepatocytes as primary culture of these cells have short-term survival.

In conclusion, our findings altogether indicate that, other than in muscle and neural tissues, the 'locally acting' IGF1 isoform may be important in modulating proliferation and response to damage also in liver cells. This should stimulate genic or pharmacologic strategies focused at enhancing the expression of 'locally acting' IGF1 isoform in liver cells as therapeutic options in cholestatic liver diseases where the cytotoxic effects of accumulating BS is a major cause of liver damage and disease progression.

\section{ACKNOWLEDGEMENTS}

We thank F Lucarelli and Cinzia Tesse for technical assistance in immunoblotting and Tracie Dornbusch for English editing. Dr Alpini was supported by the Dr Nicholas C. Hightower Centennial Chair of Gastroenterology from Scott \& White, the VA Research Scholar Award, a VA Merit Award and the NIH grants DK58411 and DK062975. D Alvaro was supported by MIUR grants: 2005: 2005067975_002.

\section{DISCLOSURE/DUALITY OF INTEREST}

The authors have nothing to disclose in relationship with the content of the present paper.

1. Jones Jl, Clemmons DR. Insulin-like growth factors and their binding proteins: biological actions. Endocr Rev 1995;16:3-34.

2. Sepp-Lorenzino L. Structure and function of the insulin-like growth factor I receptor. Breast Cancer Res Treat 1998;47:235-253.

3. Butler AA, LeRoith D. Minireview: tissue-specific versus generalized gene targeting of the igf1 and igf1r genes and their roles in insulin-like growth factor physiology. Endocrinology 2001;142:1685-1688.

4. Giustina A, Veldhuis JD. Pathophysiology of the neuroregulation of growth hormone secretion in experimental animals and the human. Endocr Rev 1998;19:717-797.

5. Tumber A, Meikle MC, Hill PA. Autocrine signals promote osteoblast survival in culture. J Endocrinol 2000;167:383-390.

6. Ge NL, Rudikoff S. Insulin-like growth factor I is a dual effector of multiple myeloma cell growth. Blood 2000;96:2856-2861.

7. Hong F, Kwon SJ, Jhun BS. Insulin-like growth factor-1 protects H9c2 cardiac myoblasts from oxidative stress-induced apoptosis via phosphatidylinositol 3-kinase and extracellular signal-regulated kinase pathways. Life Sci 2001;68:1095-1105.

8. van Golen CM, Feldman EL. Insulin-like growth factor I is the key growth factor in serum that protects neuroblastoma cells from hyperosmotic-induced apoptosis. J Cell Physiol 2000;182:24-32.

9. Chen $\mathrm{H}$, Yan GC, Gishizky ML. Identification of structural characteristics that contribute to a difference in antiapoptotic function between human insulin and insulin-like growth factor 1 receptors. Cell Growth Differ 1998;9:939-947.

10. O'Connor R, Kauffmann-Zeh A, Liu YM. Identification of domains of the insulin-like growth factor I receptor that are required for protection from apoptosis. Mol Cell Biol 1997;17:427-435.

11. Musaró $A$, McCullagh $K$, Paul $A$, et al. Localized lgf-1 transgene expression sustains hypertrophy and regeneration in senescent skeletal muscle. Nat Genet 2001;27:195-200. 
12. Hameed M, Orrell RW, Cobbold M, et al. Expression of IGF-I splice variants in young and old human skeletal muscle after high resistance exercise. J Physiol 2003;547:247-254.

13. McCall GE, Allen DL, Haddad F, et al. Transcriptional regulation of IGF-I expression in skeletal muscle. Am J Cell Physiol 2003;285:C831-C839.

14. Wang $X$, Yang Y, Adamo ML. Characterization of the rat insulin-like growth factor I gene promoters and identification of a minimal exon 2 promoter. Endocrinol 1997;134:1528-1536.

15. Pfaffl MW, Mirkeva Georgieva T, Penchev Georgiev I, et al. Real-time RT-PCR quantification of insulin-like growth factor (IGF)-1, IGF-1 receptor, IGF-2, IGF-2 receptor, insulin receptor, growth hormone receptor, IGF-binding proteins 1, 2 and 3 in bovine species. Domest Anim Endocrinol 2002;22:91-102.

16. Barton ER, Morris L, Musaro A, et al. Muscle-specific expression of insulin-like growth factor I counters muscle decline in mdx mice. J Cell Biol 2002;157:137-148.

17. Aperghis M, Johnson IP, Cannon J, et al. Different levels of neuroprotection by two insulin-like growth factor-I splice variants. Brain Res 2004;1009:213-218.

18. Musaro A, Rosenthal N. Maturation of the myogenic program is induced by postmitotic expression of insulin-like growth factor I. Mo Cell Biol 1999;19:3115-3124.

19. Dobrowolny G, Giacinti C, Pelosi L, et al. Muscle expression of a local Igf- 1 isoform protects motor neurons in an ALS mouse model. J Cell Biol 2005;17:193-199.

20. Barton-Davis ER, Shoturma DI, Musaró A, et al. Viral mediated expression of insulin-like growth factor I blocks the aging-related loss of skeletal muscle function. Proc Natl Acad Sci USA 1998;95: 15603-15607.

21. Barton-Davis ER, Shoturma DI, Sweeney HL. Contribution of satellite cells to IGF-I induced hypertrophy of skeletal muscle. Acta Physiol Scand 1999;167:301-305.

22. Kaspar BK, Llado J, Sherkat $\mathrm{N}$, et al. Retrograde viral delivery of IGF-1 prolongs survival in a mouse ALS model. Science 2003;301:839-842.

23. Butler AA, LeRoith $D$. Minireview: tissue-specific versus generalized gene targeting of the igfl and igfir genes and their roles in insulin-like growth factor physiology. Endocrinology 2001;142:1685-1688.

24. Adamo ML, Farrar RP. Resistance training, and IGF involvement in the maintenance of muscle mass during the aging process. Ageing Res Rev 2006;5:310-331.

25. DeBosch BJ, Baur E, Deo BK, et al. Effects of insulin-like growth factor-1 on retinal endothelial cell glucose transport and proliferation. J Neurochem 2001;77:1157-1167.

26. Meinel L, Zoidis E, Zapf J, et al. Localized insulin-like growth factor I delivery to enhance new bone formation. Bone 2003;33:660-672.

27. Alvaro D, Drudi-Metalli V, Alpini G, et al. The intrahepatic biliary epithelium is a target of the growth hormone/insulin-like growth factor 1 axis. J Hepatol 2005:43:875-883.

28. Drudi Metalli V, Mancino MG, Mancino A, et al. Bile salts regulate proliferation and apoptosis of liver cells by modulating the IGF1 system. Dig Liver Dis 2007;39:654-662.

29. Gigliozzi A, Alpini G, Baroni GS, et al. Nerve growth factor modulates the proliferative capacity of the intrahepatic biliary epithelium in experimental cholestasis. Gastroenterology 2004;127:1198-1209.

30. Cantafora A, Blotta I, Rivabene R, et al. Evaluation of RNA messengers involved in lipid trafficking of human intestinal cells by reversetranscription polymerase chain reaction with competimer technology and microchip electrophoresis. Electrophoresis 2001;24: 3748-3754.
31. Introduction to quantitative PCR. Methods and application guide http://www.stratagene.com/.

32. Heidenreich S, Schmidt $M$, August $C$, et al. Regulation of human monocyte apoptosis by the CD14 molecule. J Immunol 1997;159:3178-3188.

33. Vera $M$, Sobrevals $L$, Zaratiegui $M$, et al. Liver transduction with a simian virus 40 vector encoding insulin-like growth factor I reduces hepatic damage and the development of liver cirrhosis. Gene Therapy 2007;14:203-210.

34. Lorenzo-Zuniga V, Rodriguez-Ortigosa CM, Bartoli $\mathrm{R}$, et al. Insulin-like growth factor I improves intestinal barrier function in cirrhotic rats. Gut 2006;55:1306-1312.

35. Castilla-Cortazar I, Garcia M, Quiroga J, et al. Insulin-like growth factor-I reverts testicular atrophy in rats with advanced cirrhosis. Hepatology 2000;31:592-600.

36. Cemborain A, Castilla-Cortazar I, Garcia M, et al. Osteopenia in rats with liver cirrhosis: beneficial effects of IGF-I treatment. J Hepatol 1998:28:122-131.

37. Prieto J, Sobrevals L, Razquin N, et al. Treatment of established cirrhosis with SV40 vectors encoding insulin-like growth factor I. Hepatology 2007;46:S1, abstract.

38. Conchillo $M$, de Knegt RJ, Payeras $M$, et al. Insulin-like growth factor I (IGF-I) replacement therapy increases albumin concentration in liver cirrhosis: results of a pilot randomized controlled clinical trial. J Hepatol 2005;43:630-666.

39. Alpini G, Lenzi R, Sarkozi L, et al. Biliary physiology in rats with bile ductular cell hyperplasia. Evidence for a secretory function of proliferated bile ductules. J Clin Invest 1988;81:569-578.

40. Buscher HP, Miltenberger C, MacNelly S, et al. The histoautoradiographic localization of taurocholate in rat liver after bile duct ligation. Evidence for ongoing secretion and reabsorption processes. J Hepatol 1989;8:181-191.

41. Muriel $P$, Gonzalez $P$. Liver damage induced by acute cholestasis in the rat is ameliorated partially by L-arginine. Comp Biochem Pysiol C pharmacol Toxicol Endocrinol 1998;120:421-424.

42. Souza ME, Castro-e-Silva Júnior O, Picinato MA, et al. Serum transaminase levels in the acute phase of chronic extrahepatic cholestasis. Braz J Med Biol Res 1990;23:995-997.

43. Georgiev $\mathrm{P}$, Jochum W, Heinrich $\mathrm{S}$, et al. Characterization of timerelated changes after experimental bile duct ligation. $\mathrm{Br} J$ Surg 2008;95:646-656.

44. Kim ND, Moon JO, Slitt AL, et al. Early growth response factor-1 is critical for cholestatic liver injury. Toxicol Sci 2006;90:586-595.

45. Alvaro D, Mancino MG, Glaser S, et al. Proliferating cholangiocytes: a neuroendocrine compartment in the diseased liver. Gastroenterology 2007;132:415-431.

46. Guicciardi ME, Gores GJ. Cholestatic hepatocellular injury: what do we know and how should we proceed. J Hepatol 2005;42:297-300.

47. LeSage EG, Alvaro D, Benedetti A, et al. Cholinergic system modulates growth, apoptosis, and secretion of cholangiocytes from bile ductligated rats. Gastroenterology 1999;117:191-199.

48. Glaser S, Benedetti A, Marucci L, et al. Gastrin inhibits cholangiocyte growth in bile duct-ligated rats by interaction with cholecystokinin-B/ gastrin receptors via D-myo-inositol 1, 4, 5-triphosphate-, $\mathrm{Ca}\left({ }^{2+}\right)$-, and protein kinase $C$ alpha-dependent mechanisms. Hepatology 2000;32:17-25.

49. Marzioni M, Glaser S, Francis $\mathrm{H}$, et al. Autocrine/paracrine regulation of the growth of the biliary tree by the neuroendocrine hormone serotonin. Gastroenterology 2005;128:121-137. 